\title{
Voice Strengthening and Interactive Theatre for Women's Productive Income-Generating Activities in Sustainable Development
}

\author{
Beth Osnes ${ }^{1}$ \\ ${ }^{1}$ University of Colorado, Boulder, USA \\ Correspondence: Beth Osnes, University of Colorado, UCB 261, Boulder, CO 80309, USA. Tel: \\ 1-1130-3492-0731. E-mail: beth.osnes@colorado.edu
}

Received: March 18, 2012 Accepted: May 1, 2012 Online Published: May 21, 2012

doi:10.5539/jsd.v5n6p49

URL: http://dx.doi.org/10.5539/jsd.v5n6p49

\begin{abstract}
This article introduces the importance of voice strengthening for women who are living in poverty and self-identify as wanting to pursue income-generating activities. Furthermore, it describes using interactive theatre to explore the various components of income-generating activities, which can support women in more fully participating in their own sustainable development. By focusing on the Voices for Change Workshop I developed and a specific application of this workshop for a group of women in Nicaragua, I offer practical methods for women to strengthen their voices, and methods for women to use their strong voices to explore possible income-generating activities. The workshop encourages women to critically engage with potential income-generating activities and to identify activities that could promote sustainability in their own lives, their environment and the world.
\end{abstract}

Keywords: gender, income generating activities, vocal strength, interactive theatre

\section{Introduction}

There are multiple barriers that keep women who are living in poverty from participating in their own sustainable development. These include, but are certainly not limited to: lack of education, fluency in the dominant language, access to land or capital, internalized oppression, social and political structures that trap women in a life of poverty, and lack of vocal strength and confidence. The final barrier, lack of vocal strength and confidence, does not appear in many scholarly considerations on gender equity and sustainable development, but I strongly believe that it is an important consideration in women's ability to participate in their own sustainable development. This article focuses particularly on women's income-generating activities as one aspect of sustainable development. By focusing on the Voices for Change Workshop I developed, and a specific application of this workshop for a group of women in Nicaragua, I offer practical methods for women to strengthen their voices, and methods for women to use their strong voices through interactive theatre to explore potential income-generating activities towards their own sustainable development. My hope is, thereby, to communicate the importance of supporting women's voices and to have development practitioners recognize these methods as valuable tools in supporting women's participation in their own sustainable development. As author Kathleen O-Reilly emphasizes, "gendered participatory approaches have grown popular as project planners seek ways to incorporate women's knowledge and labor into development projects" (2006).

The World Commission on Environment and Development in 1987 defined the phrase 'sustainable development' as, "development which meets the needs of the present without compromising the ability of future generations to meet their own needs" (1987). The consideration of achieving sustainable development in relationship with gender equity has certainly increased in prominence in the last decades. Author Gerd Johnsson-Latham conducted a study examining to what extent women live in a more sustainable way and leave a smaller ecological footprint than men, and why and how gender equality is essential to sustainable development (Johnsson-Latham, 2007).

\section{Materials Studied}

\subsection{Gender and Sustainable Development}

The marriage of gender with global initiatives-such as the Millennium Development Goals-highlighted the importance of gender equity in achieving sustainable development and the reduction of poverty. It is striking 
how frequently gender is named in the context of poverty alleviation strategies (Rodenberg, 2004). UNICEF's report, The State of the World's Children 2007: Women and Children, the Double Dividend of Gender Equity, states that "Gender equality will not only empower women to overcome poverty, but also their children, families, communities and countries. When seen in this light, gender equality is not only morally right - it is pivotal to human progress and sustainable development. Moreover, gender equality produces a double dividend: It benefits both women and children" (viii). According to author Daraka Chhay, since women are more likely to spend their income on improving the family situation, their economic empowerment benefits their children, "who are generally more likely to attend school and have better nutrition" (2011).

Women have become prominent targets for empowerment initiatives and they are frequently staged by development agencies as agents of change (Bieri, 2009). In the last few decades, spurred on by the successes of innovators like Bangladeshi economist Muhammad Yunus-who developed a system of microcredit loans given primarily to women through the Grameen Bank (Yunus, 2007)-many development agencies are increasing their emphasis on assisting women to secure income through their own efforts, which are "often categorized as 'income-generating activities' and cover initiatives as diverse as small business promotion, cooperative undertakings, job creation schemes, sewing circles, credit and savings groups and youth training programmes" (Albee, 1994). Income-generating activities can be defined as "initiatives that affect the economic aspects of people's lives through the use of economic tools such as credit" (2). Some prefer the use of the phrase "women's productive activities'. In 1994 UNICEF began to use the phrase 'women's productive activities' and joined a general, but not unanimous, move by development agencies away from the use of the phrase 'income-generating activities' because it continued to conjure up images of women undertaking marginal economic activities far removed from gender issues and the goal of women's empowerment (Albee, 1994). I will utilize the phrases 'women's productive income-generating activities' and 'income-generating activities' to be sufficiently descriptive and inclusive of both phrases.

However, caution and deep consideration of women's lives should be considered in making them the focus of so much development attention, as the result can be the piling of more work on an already oppressed and impoverished population. The promotion of income-generating activities should be approached carefully because of the "ways in which earning money may extend women's options, but may also intensify their workload and responsibilities without necessarily increasing their autonomy (Pearson, 2007). In one study it was noted how most of the working mothers had little or no access to the income they generated (Abbi et al., 1991). It is also possible that the money earned can result in a decreased contribution from a husband who resents being displaced as the family provider, increased domestic violence and other unintended negative consequences (Ellson, 1999). Yet for women assuming the sole responsibility for the welfare of their families, these issues are less relevant.

Thus, it is with the acknowledgment that income-generating activity is anything but a quick fix for improving women's lives, but that, regardless, many women living in poverty desire to, and can, fulfill some of their own and their family's needs by initiating income-generating activities. Furthermore, as I hope this article indicates, these efforts can, when partnered with vocal strengthening and rehearsal of strong voices through interactive theatre, contribute to a woman's transformation from a passive recipient of her prescribed reality, to an actor/author in scripting her possible future. She can also, when facilitated in critically exploring her options, attempt to design income-generating activities that not only help her work her way out of poverty, but also are aligned with her values and ultimately contribute towards the sustainability of her family, community and world.

\subsection{Theatre for Development}

In this work I draw upon the theory, practice and techniques of Theatre for Development, which uses theatre as a way of engaging a community in a workshop setting to catalyze action and change (McCarthy, vii). Theatre for Development has many names and is applied in many fields by professionals in a variety of disciplines. Those working in public health often refer to these techniques as Behavior Change Communication (Salem, 2008). Those in fields such as geography refer to it as theatre-based Participatory Development (McCarthy). Theatre practitioners most often referred to it as Theatre of the Oppressed, Theatre for Social Change, Theatre for Development, or more recently, under the umbrella phrase, Applied Theatre (Prentki). All of these forms use theatre as a way to engage marginalized people-most often in non-traditional performance spaces-to participate in transforming their own lives.

Augusto Boal is credited with being the founder of this type of work by drawing upon the writing of educational theorist Paulo Freire (Freire) to develop techniques for using theatre as a dialogue and an opportunity to act out social change. His creation of Forum Theatre, in which he transforms passive spectators into agents of change, or 
'spect-actors' revolutionized theatre for social change. In Forum Theatre anyone present can interrupt the action, replace an actor, and change the direction of the action. "In forum theatre no idea is imposed: the audience, the people, have the opportunity to try out all their ideas, to rehearse all the possibilities, and to verify them in practice, that is, in theatrical practice... It is not the place of the theatre to show the correct path, but only to offer the means by which all possible paths may be examined (Boal, 1985)." His seminal book Theatre of the Oppressed was the catalysis for subsequent work and development in this field.

\subsection{Area Description: Site and Population Description}

The Central American country of Nicaragua is situated between Honduras to the north and Costa Rica to the south. The host organization for this intervention was the American Association for the Care of Children (AACC) that promotes support for those involved in early childhood care and education, through educational programs and projects. Participants for the workshop were drawn from two primary AACC programs. Twelve workshop participants were from the Programa Integral Educando con Amory Tenure (PIEAT), situated in the northern village of Jalapa, engaging local women in grassroots relationship and democracy building through early education childhood care and educational initiatives. It should be noted that the PIEAT group is a fairly sophisticated and informed group of already empowered women who have received extensive training in early childhood education, social work and community development practices. Thirteen workshop participants were from a program at La Chureca, the largest landfill in Managua, home to more than 1,500 people, some of whom have been living there since the late 1960s and most of whom live on about \$1 to \$2 US a day. Many of these women were experienced community organizers and some were less involved and experienced in social action initiatives.

The two-day intensive Voices for Change Workshop took place in the capital city Managua, at the Karios Center for Formation, from 8:30 AM to 5:00 PM each day. Karios itself is engaged in community development and was founded on the principles of liberation theology; given it has the same theoretical foundation from which Freire wrote, it was extremely supportive of this workshop. The women from the Jalapa PIEAT program resided at the Karios center during the workshop, along with myself, AACC's founder and executive director, Debbie Young, and other volunteers. The actual workshop took place in an outdoor roofed structure with no walls on the Karios grounds.

All of the participants were community leaders to varying degrees-evident by their participation in the AACC programs-but all also lived at an extremely low-income level. I was told by an AACC employee that most participants didn't own their own homes, probably could not afford three meals a day, and had very low levels of education and no access to health care, other than when giving birth. Two of the women in the workshop brought their young daughters, and one PIEAT woman from Jalapa who couldn't make it, due to bad health, sent her 18 -year-old son in her place.

\subsection{Methods}

When planning this intervention with Debbie Young, in the months preceding its implementation, she said that all of the participants were primarily interested in strengthening their voices towards the ultimate goal of improving their ability to generate income for their families. The women in Jalapa wanted their program to be financially sustainable (which would then ensure and, perhaps, increase their modest stipends). Thus, I designed a 2-day workshop for this intervention that first focused on vocal strength and confidence, and secondly on using this strong voice to explore and critically engage with key aspects of successful income-generating models from around the world. Recognizing that income generation is a very difficult and multifaceted process, the goal of this workshop was simply to begin to involve these women in their own sustainable development by strengthening their voices for participation and to practice using these voices to explore key aspects of successful income-generating activities.

\subsection{Techniques: Planning this Intervention}

The planning for this intervention began in October of 2011 between Debbie Young and myself. Debbie had heard of the workshop I had developed for women to strengthen their voices and was interested in hosting this for the groups of Nicaraguan women she works with through AACC. She, and the women in Nicaragua, were primarily interested in applying this process to income-generating activities. My goal was to provide technical input for these already cohesive and relatively trained groups of community leaders who would be supported by the AACC programs to support and deepen the practice of the work. I learned from Debbie that the La Chureca women were already engaged in making small purses and earrings out of recycled plastic packaging to sell-almost exclusively to tourists. Debbie expressed her desire for the women to explore other income-generating possibilities that did not perpetuate dependency on people and markets outside Nicaragua, 
namely rich tourists from the USA. Since I have most recently used my vocal workshop on the Navajo Nation, for a Women's Energy Project that helps women strengthen their voices for participation in generating income by selling solar-powered lights, I shared with Debbie the possibility of using solar-powered lights as an example in the workshop setting, especially as access to energy is such an important aspect of development (Clancy et al., 2007). Nokero is a company in Denver with whom I have already worked, so their relatively inexpensive solar-powered light bulbs seemed like a natural choice. Debbie thought that this would be a good idea for expanding the participants' ideas of possible activities, since access to energy was also an important issue facing many families in Nicaragua. I realize that it is not realistic to think of taking a project design that is working in one cultural context and replicate it in another very different cultural context. My intention was to simply use this clean energy technology as an example for the women to consider for themselves and to use their voices to explore and critique within their cultural context in the workshop setting. Before traveling to Nicaragua I was also able to meet with Edis Cardoza Blondon who is Nicaraguan and an AACC staff member residing in Jalapa, to consult with me on the design for the workshop. Upon arriving in Nicaragua in January of 2012, I was able to thoroughly go over the plans for the workshop again with Edis-who would serve as the translator-receiving further feedback as to the workshop design and content, and to practice for the following days.

When designing the workshop, I relied upon the structure of the Voices for Change Workshop that I have been continually developing and refining for various types of populations during the last four years. The first day focused on vocal strengthening and gaining vocal confidence by rehearsing acting on self-identified concerns through interactive theatre. Much of that content was informed by being a professor of theatre and a teacher of acting and performance, including the theoretical knowledge and practical experience gained from that experience. When designing the second day of the workshop, I primarily relied upon my experience with the Navajo Women's Energy Project, projects I have learned about through conferences, and a thorough review of literature on women's productive and income-generating activities.

\subsection{Implementation of Design for Workshop- $1^{\text {st }}$ Day}

In Managua, I implemented this design for strengthening voices with the Nicaraguan women in AACC projects via the following practices. On our first day, after introducing myself and stating the goals for our time together, we began with warm-up exercises to get to know each other's names and to begin to feel comfortable being expressive together. As always, I asked that we arrange ourselves in a circle. These beginning exercises were aimed at simultaneously energizing the space and creating a safe place together to be expressive and to try new behaviors. It was also designed to intentionally nurture community coming together to encourage sustaining each other's strong voices in the future. My attempt was to engage both their bodies and voices with each exercise, such as saying an open "Ahhh" sound at the very bottom of their vocal range with their hands held low near their knees, and to bring their hands up as high as they could go while they slid vocally to the very top of their range, all in one breath.

Our next focus was on relaxation for a strong voice to release tension which blocks expression and to allow expression to flow out into the entire body. Standing upright, I asked participants to allow their head to fall forward and to continue to allow the head to pull them down, slowly through the spine, one vertebrae at a time, until they where completely slumped over with hands nearly touching the ground, and then build up the spine again, starting at the tailbone, all the while keeping the head, arms and shoulders relaxed. After doing exercises for full breath, we did an exercise of vocalizing on a yawn to open their throats, since throat muscles often constrict and censor the voice when it becomes emotional or nervous. By repeatedly stretching our faces open and then pinching them closed we increased the expressivity of our faces for a strong voice. We experimented with volume in several exercises to explore that component of a strong voice. Finally, we did exercises for authentic eye contact-giving direction to our strong voices by trying to incorporate and maintain the benefits of all the previous exercises while making eye contact. Next, I asked participants to stand across from a partner while maintaining eye contact and to declare in a strong voice-at twice the volume they would usually use-their most passionate social concern facing their lives, their community, their nation or the world. Returning to our circle, I asked them to repeat that concern one at a time to the entire group, making authentic contact with each person in the circle.

Since one of the goals of the workshop is to encourage critical engagement, I stopped the action at this point and invited participants to reflect on their feeling of this expanded voice they all just experienced. I asked them to share with each other how they felt about their voices as strong and what it might be like to use this voice in their daily lives. I asked what might change for the better, or for the worse, if they did. This also served the purpose of allowing the participants to understand how other participants felt about their voices, which is important if they are to effectively support each other's voices in their communities. For this workshop I introduced a way for 
each women to measure her own feeling about her voice by creating a vertical chart with the numbers one to ten and a correlating drawing of a woman on top near the one with her mouth wide open happily speaking, a woman near the five looking moderately confident speaking, and a woman near the ten not speaking at all. Each woman was asked to use her hand to indicate where she would rate her feeling of her voice in three different situations-in the workshop setting, at home with her family, and in a public setting-on the chart. The chart was large enough for everyone to see in the circle, so I walked around to each woman with the chart to have her indicate how she felt in each setting.

During the second half of that day, we devised ways that we could act on these concerns using our strong voices and practiced new possibilities for using a strong voice in real-life situations by using interactive theatre techniques. The most pressing concern of the group that emerged was domestic violence, so together we rehearsed one woman trying to use her voice to report on and then confront her husband about his abuse, with workshop participants taking the various roles and commenting on the action. Throughout this process, we tried to focus on different strategies for solving one single persistent problem, exploring many different ways participants could use their voices, such as alone, in groups, or on behalf of each other.

\subsection{Implementation of Design for Workshop-2 ${ }^{\text {nd }}$ Day}

At the beginning of the second day of the workshop, I stated that the goal for the day was for women's voices to participate in income-generating activities and for women to use their voices to critically engage with different ideas for income-generating activities. I acknowledged that such activities are extremely difficult, need continual support, and take a lot of research and testing. I stated that we would simply be starting the process by introducing and exploring common components of women's income-generating activities, and that we would be exploring two possible products for income generation to consider within these components. The first component that I introduced for exploration was a women's support group, which are sometimes referred to as solidarity groups (Albee, 1994) and often overseen by an NGO or governmental agency to provide support, training and sometimes even loans. To explore being in such a group and having to share decision making, I asked the participants to divide into four groups and to begin by deciding on a name for their group together. Next, I asked the groups to try a trust exercise in which they all stood close together with one person in the middle of the circle with her arms crossed against her chest and her eyes closed. I asked that center person to let herself continually fall off balance, relying on the rest of the group to keep her from falling.

The next component we explored was market analysis and so I asked the women from La Chureca if we could use the various purses and earrings they made from recyclables to conduct a brief market analysis on each of these products. There were four products, a different one for each group, that consisted of earrings, a small, recycled coin purse, a larger recycled purse, and a shopping bag sewed of cloth. I asked each group to identify their target market for their product by considering: who they thought would want to buy this product; if they would forecast any growth predictions for this market; and if they saw any trends with this market. Once each group had done that, we had them briefly report their results to the rest of the group so we could experience analyzing the competition.

Then, in more of a discussion format, I introduced the components of capital-the need for some seed money or a loan through microcredit-and together we discussed possible outlets for attaining capital. Finally, we discussed the components of sustainability, both in terms of the long-term resilience of the marketing plan, but also the sustainability of the activities as being healthy for the environment or taking from and/or destroying natural resources. After lunch, we repeated this process with the Nokero solar-powered light bulbs as the product, instead of the recycled purses and earrings. We concluded the day by comparing and contrasting the two different products in light of the components of income-generating activities.

\section{Results: Outcomes of Intervention}

\subsection{Outcomes for $1^{\text {st }}$ Day}

One of the outcomes of the first day was that, by arranging myself and the other participants in a circle for most of the workshop, we were able to share power and dismantle hierarchies more successfully than we might have in a more classroom-type setting, with me in the front and the participants all facing me. This was made evident in one way by the fact that the women offered comments when they felt inspired to do so, without consulting me for approval or permission. Another outcome, as expressed by the participants themselves, was that they began to see their lives and their condition as women as more malleable that they had previously imagined-not set in stone. They stated that previous to the workshop they knew that they wanted to change their lives and, indeed, had been acting on that account, but in the workshop they increased in their awareness of how their voices could be a powerful tool for doing this. They also realized that they could help each other have strong voices by 
supporting each other and by practicing to have strong voices by doing the vocal exercises from the workshop. In fact, in an email correspondence from Debbie following the workshop, when she had returned to Jalapa with the PIEAT women in the workshop, she said that she had witnessed them rehearsing the exercises each morning together and sharing them with other women in their village during the PIEAT's home visits.

When the women were asked to critically engage with their feelings about their voices, I think that the exercise of marking on the chart their feelings in the workshop, with their family at home, and in a public setting was useful. Each woman seemed to give it a lot of consideration as she marked a level for each feeling on the chart, and a lot of conversation emerged at the end of this exercise as to their generalized feelings about their voices. One woman noted that because there is so much domestic violence, that the rating of feeling of voice in home could be hard to determine. A woman might be thinking of talking with her kids, her sisters and mother, or an abusive husband. The average rating ( 1 being most confident and 10 least confident) for the workshop participants for the felling of their voices is as follows: in the workshop setting 2.8 , at home with family 2.1 , and in a public setting 4 .

\subsection{Outcomes for $2^{\text {nd }}$ Day}

On the second day of the workshop, focused on income-generating activities, the support groups were all successful in creating names for themselves. These included: To Know is Sharing; Love Links; Solidarity Group with Love and Peace; and The Eagles. When asked how they worked together to share decision making, they all described various democratic methods for listening to each member's suggestions and deciding through a process of consensus.

The outcome of the trust exercise, in which one person in the support group was literally supported by the others as she continually fell off balance, was that participants identified how important it was to be responsible as part of a support group in helping each other. Many of the women said that they were happy to have experienced both roles-the supporter and the person being supported. Another participant added that the person being supported had a responsibility too: to not put too much of her weight on the group and cause undue stress on the group. Another woman noted that when someone is missing in the group that it is harder on the others and makes the others feel more vulnerable.

One of the outcomes of the market analysis exercise with the two products, was that each group was able to successfully identify and present to the group a target market and to describe that market. One of the women commented that she appreciated being able to participate in this portion especially, and not just have it be ideas swimming around in her head. The women were supportive and seemed engaged and interested in both products, but they were particularly responsive to the solar-powered lights, since the technology was new to them, and they identified it as answering a real need for access to energy in their communities. With funds raised to cover this workshop, I had purchased and brought enough light bulbs to give one to all the workshop participants to use in their own lives and further consider as a possible product. I was careful to explain to the women that I had no intention of promoting this particular product, but that it is a product used in other projects for the purpose of women's income-generating activities. In the workshop, Debbie added that she had asked me to share ideas I had used in other projects that were specifically focused on clean energy development. In meeting with Debbie in the weeks following the workshop, I learned that the women in Jalapa took their Nokero solar-powered lights with them on their home visits and that nearly everyone who interacted with the technology in the Jalapa region wanted to buy a light. Debbie applied a few of the tools we used in our lessons on market analysis with the women, and they realized that if they each sold only 4 lights a week with a 50\% mark up that they could double the modest stipend each woman received from the program. Therefore, the PIEAT program will be looking into designing and testing a program for selling solar-powered lights as an outcome of this workshop experience.

Another outcome was that the women seemed to understand and value the interactive theatre as a tool for exploring income-generating ideas. After two women had acted out trying to sell the solar-powered lights door to door, I asked the group if anyone had feedback about that scene or if they had other ideas for selling the lights. One woman raised her hand, but instead of explaining her idea to sell the lights in the market, began directing the other women to help her act out her idea. She not only successfully directed the women in acting out her idea, but my assumption is she felt that interactive theatre helped her communicate her idea more effectively than simply describing it.

\section{Discussion: Lessons Learned}

A lesson that has been consistently underscored as I've conduct my Voices for Change Workshop in different countries for various organizations, is that this relatively short-term intervention is likely to be effective and useful only if the fundamental theoretical foundation of the workshop (Freire, 1970; Boal, 1985) is shared by the 
host organization and if the host is committed to supporting and deepening the practice of this vocal strengthening work. In this case, the workshop, AACC and even the Karios Center, were all aligned in believing in the women's ability to transform their own lives through participation in their own development, and the women themselves in the PIEAT program-with whom I have more continued feedback-took control over continuing and deepening the work.

From the focus group with seven of the participants the morning after the workshop, we learned that the women believed that voice was a very important part of succeeding in generating income. One woman said, "If a woman has resources but has no voice, she won't be able to do anything with those resources." Another woman added that she was glad to learn of the many ways to strengthen her voice besides just getting louder and yelling.

Based on my own observation of levels of engagement during the workshop, I learned that the second day of the workshop could be improved by introducing more methods for making the exploration of capitol and sustainability more active, as the active lessons of the components of income-generating activities seemed to be the most effective. In addition-based on my observation, feedback from the women in the focus group and an AACC staff member-our exploration of market analysis could be made more rigorous and nuanced. A practical understanding of this component, and development of needed skills, would be greatly supported by actually doing an effective analysis of their market. Edis, an AACC staff member, suggested having the workshop take place over multiple weekends so participants could use and try new skills, and then come back with questions and further ideas to try out. Certainly, the cursory introduction supplied by the workshop would need to be advanced by efforts of the sponsoring NGO or governmental organization, to successfully involve participants in doing an effective analysis of their market for various products with qualified experts in that field.

I was concerned that introducing the Nokero solar-powered light bulbs-a slick technology engineered in the USA and made in China-would make the women's recycled purses seem less desirable, which is why I purposefully introduced the purses first. However, I could see the women visibly considering the options and discussing both product ideas in an engaged manner, especially when I told them how much capital they would need to raise to get a shipment of the lights to Nicaragua, compared to the relatively small amount of capital required to make the purses.

When considering sustainability at the end of the second day, what we all learned was that the solutions for income-generating activities-such as items made from recycled materials and solar-powered lights-can be the same solutions for our lives, our planet and our future, such as less garbage in the land fills and clean energy that doesn't pollute. We get a double dividend, in terms of sustainability, if the products being sold in income-generating activities raise women out of poverty and are also good for our environment. A few of the women also noted that income-generating activities that were in-line with their values, would also help sustain their commitment and dedication to pursuing this income-generation activity. They compared this to a growing trend of women selling cosmetics door-to-door to women who are living in poverty, and how that did not add any value to their community, but, rather, took resources away from other more legitimate needs.

\section{Conclusion}

While fully acknowledging that there are many factors to monitor in terms of a woman's overall life being improved by income-generating activities, for women living in poverty who self-identify as wanting to initiate an income-generating activity, the use of interactive theatre can be an effective tool for introducing necessary aspects of such an endeavor. In my experience, sharing tools for strengthening voices increases confidence and the likely success of these efforts. I hope to continue this research by focusing on the ability of vocal strengthening to address internalized oppression for women living in poverty. Researcher Sabin Bieri argues that "income generating activities for women may lead to empowerment, improved livelihoods, higher living standards and welfare for rural households if a more comprehensive framework is applied" (2009). What this article demonstrates is that part of that comprehensive framework could include methods to strengthen women's voices and confidence by practicing using those voices to devise solutions for their own sustainable development. These efforts could help foster transformation in a dramatic way-in each woman individually and in communities of women working to support each other's strong voices. As women actually feel the power of their voices-and practice using these strong voices to participate in imagining and critiquing new income-generating possibilities-they become authors, actors and participants in improving their own lives. 


\section{References}

Abbi, R., Parul, C., Sunder, G., \& Tara, G. (1991). The impact of maternal work status on the nutritional and health status of children. Food and Nutrition Bulletin, 13(1). Retrieved January 20, 2012 from http://www.greenstone.org/greenstone3/nzdl;jsessionid=30E1179E23E49C5BB070489CBA1A9078? $\mathrm{a}=\mathrm{d} \&$

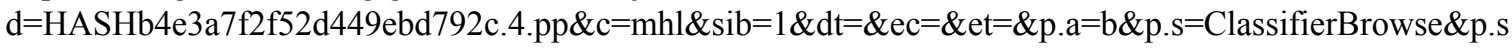
$\mathrm{a}=. \mathrm{html}$

Albee, A. (1994). Support to women's productive and income-generating activities. Evaluation and Research Working Paper Series, 1, (UNICEF). Retrieved January 12, 2012, from http://www.gdrc.org/icm/wind/wind-unicef-wp.html

Bieri, S. (2009). Power and poverty. Reducing gender inequality by ways of rural employment? In FAO-IRAD-ILO Workshop on Gaps, trends and current research in gender discriminations of agricultural and rural employment: differentiated pathways out of poverty. Symposium conducted at the meeting of the FAO-IFAD-ILO, Rome, Italy.

Boal, A. (1985). Theatre of the oppressed (C. A. McBride \& M. O. L. McBride, Trans.). New York, NY: Theatre Communications Group.

Chhay, D. (2011). Women's economic empowerment through microfinance in Cambodia. Development in Practice, 21, 1122-1137. http://dx.doi.org/10.1080/09614524.2011.606891

Clancy, J., Ummar, F., Shakya, I., \& Kelkar, G. (2007). Appropriate gender-analysis tools for unpacking the $\begin{array}{lllll}\text { gender-energy-poverty nexus. Gender \& Development, } & 15, \quad 241-257 .\end{array}$ http://dx.doi.org/10.1080/13552070701391102

Elson, D. (1999). Labor markets as gendered institutions: equality, efficiency and empowerment issues. World Development, 27, 611-627. http://dx.doi.org/10.1016/S0305-750X(98)00147-8

Freire, P. (1970). Pedagogy of the oppressed (M. B. Ramos, Trans.). New York, NY: Herder and Herder.

Harris, J. (2000). Basic Principles of Sustainable Development. Medford, MA: Global Development and Environmental Institute, Tufts University.

Johnsson-Latham, G. (2007). A study on gender equality as a prerequisite for sustainable development. Report to the Environment Advisory Council, Sweden. Stockholm: The Environmental Advisory Council.

McCarthy, J., \& Galvao, K. (2004). Enacting participatory development: Theatre-based techniques. Sterling, VA: Earthscan.

Moccia, P. (2006). The State of the World's Children 2007: Women and Children, The Double Dividend of Gender Equality. New York: UNICEF.

O'Reilly, K. (2006). Women fieldworkers and the politics of participation. Signs: Journal of Women in Culture \& Society, 31, 1075-1098.

Pearson, R. (2007). Reassessing paid work and women's empowerment: Lessons from the global economy. In Feminism in development. Contradictions, contestations and challenges. Edited by Andrea Cornwall, Elizabeth Harrison and Ann Whitehead. New York: Zed Books.

Prentki, T., \& Preston, S. (2009). The applied theatre reader. New York, NY: Routledge.

Rodenberg, B. (2004). Gender and poverty reduction: New conceptual approaches in international development cooperation. In Reports and Working Papers. Bonn: German Development Institute GDI.

Salem, R. M., Bernstein, J., \& Sullivan, T. M. (2008). Tools for behavior change communication. INFO Reports, 16. Baltimore, MD: Johns Hopkins Bloomberg School of Public Health, Center for Communication Programs.

World Commission on Environment and Development. (1987). Our Common Future. Oxford: Oxford University Press.

Yunus, M. (2007). Banker to The Poor: Micro-Lending and the Battle Against World Poverty. New York: Public Affairs. 